\title{
Isolation And Identification Of Antioxidant Compounds Leaf Betel Seating (Piper sarmentosum Roxb. Ex Hunter)
}

\author{
Hartiwi Diastuti ${ }^{\mathrm{a}}$, Eva Vaulina Yulistia Delsy ${ }^{\mathrm{b}}$ \\ ${ }^{a}$ Program Studi Kimia Jurusan MIPA FST Universitas Jenderal Soedirman, hartiwidiastuti@yahoo.com \\ bProgram Studi Kimia Jurusan MIPA FST Universitas Jenderal Soedirman, evasyamsumar@yahoo.com
}

\begin{abstract}
Sirih duduk or Piper sarmentosum Roxb. ex Hunter have been long used the people in Indonesia for traditional medicine to cure various diseases. This research was aimed to isolate and identify antioxidant compounds from $P$. sarmentosum leaves. The isolation bioactive compounds of $P$. sarmentosum leaves was performed by extraction the powder of $P$. sarmentosum leaves using methanol. The methanol extract was fractionated using n-hexane and ethylacetate in their various composition. The fractions respectively was examined their antioxidant activity. The most active extract was fractionated again performed by coloumn chromatography Identification of the bioactive compounds was carried out using ultraviolet-visible (UV-Vis) spectrometry, infra red (IR) spectrometry and gas chromatography-mass spectrometry (GCMS). The result showed that the methanol extract of $P$. sarmentosum leaves have antioxidant activity. The fractionation was performed by coloumn chromatography using n-hexane-ethylacetate (4:6) eluent, a bioactive compound of sinamic acid derivative was 4-ethoxy-2-hidroxy-3,5-dimethoxy sinamic acid could be purely isolated.
\end{abstract}

Keywords: Piper sarmentosum, antioxidant, sinamic acid derivative. 